\title{
R9 - Avaliação de proteínas recombinantes nacionalizadas como componentes de um multiteste para triagem sorológica de doadores de sangue
}

Christiane de Fátima Silva Marques ${ }^{1 \star}$; Bernardo Oliveira Loureiro ${ }^{1}$; Leila Botelho Rodrigues da Silva'; Marcelle Bral de Mello ${ }^{1}$; Edimilson Domingos da Silva ${ }^{1}$; Leonardo Foti ${ }^{2}$; Marco Krieger ${ }^{3}$; Nilson Ivo Tonin Zanchin ${ }^{4}$.

1 - Bio-Manguinhos/Fiocruz;

2 - IBMP;

3 - IBMP e ICC/Fiocruz;

4 - ICC/Fiocruz.

\section{Introdução:}

A nacionalização de insumos é uma iniciativa alinhada com a política nacional de ciência e tecnologia e com as ações para o fortalecimento do Complexo Econômico-Industrial da Saúde, cujos resultados positivos incluem a capacitação técnica das instituições brasileiras e a incorporação de conhecimento relevante aos laboratórios produtores nacionais. Uma das vertentes do projeto de desenvolvimento de um ensaio múltiplo para a triagem sorológica de doadores de sangue, impulsionado pelas equipes de Bio-Manguinhos, ICC/Fiocruz e IBMP, inclui a nacionalização de proteínas recombinantes (antígenos) que possam ser utilizadas em imunoensaios destinados à detecção de anticorpos em amostras de plasma e soro humano. Uma vez comprovado o seu desempenho e valor preditivo, estas moléculas poderiam ser incorporadas a conjuntos diagnósticos (kits), substituindo opções comerciais importadas. Em última instância, essa incorporação de insumos nacionais pode gerar economia de divisas, contribuindo para a redução do déficit na balança comercial do setor saúde, bem como reduzindo a dependência externa e consolidando expertise nos grupos da Fiocruz.

\section{Objetivo:}

O presente trabalho tem como objetivo avaliar, de forma comparativa, o desempenho de proteínas recombinantes nacionalizadas diante de antígenos comercialmente disponíveis, usando um ensaio múltiplo baseado na plataforma de microarranjos líquidos como modelo de estudo. 


\section{Metodologia:}

21 proteínas recombinantes desenvolvidas e produzidas no IBMP e no ICC/ Fiocruz foram acopladas a microesferas paramagnéticas e utilizadas como moléculas de captura em um imunoensaio múltiplo, utilizando um painel interno de amostras de referência, a fim de que fosse determinado seu valor preditivo na detecção de anticorpos anti-HBV, anti-HCV, anti-HIV, anti-HTLV, anti-Treponema pallidum e anti-Trypanossoma cruzi. Em seguida, os resultados obtidos com os antígenos nacionalizados foram comparados àqueles alcançados com insumos comerciais, adotados como componentes do protótipo de multiteste em desenvolvimento. Todos os resultados foram analisados por meio da curva ROC e, a partir dela, calculados os valores de sensibilidade, especificidade, valores preditivos positivo e negativo.

\section{Resultados:}

Esta avaliação indicou que seis antígenos nacionalizados (dois de T.pallidum, dois de T. cruzi, um de HCV e um de HTLV) apresentaram desempenho igual ou superior aos correspondentes comerciais, permitindo a substituição de $1 / 3$ dos insumos importados neste imunoensaio. Os antígenos que não apresentaram a eficiência necessária serão otimizados com relação à purificação e às condições dos ensaios imunológicos. Além disso, outras proteínas estão em fase final de desenvolvimento e poderão ser avaliadas em um segundo momento, com o objetivo de aumentar a representatividade dos insumos nacionalizados no produto final.

\section{Conclusão:}

A incorporação de proteínas recombinantes nacionalizadas tem o potencial de reduzir custos e ampliar o domínio sobre a cadeia de suprimentos deste e de outros reativos para diagnóstico produzidos em Bio-Manguinhos.

Palavras-Chave: imunoensaios; diagnóstico multitestes 